\title{
The effect of dietary inclusion of conjugated linoleic acid in finishing hog feed on sensory characteristics and storage quality indicators of pork loin
}

\author{
Kaitlin Hope Maditz \\ West Virginia University
}

Follow this and additional works at: https://researchrepository.wvu.edu/etd

\section{Recommended Citation}

Maditz, Kaitlin Hope, "The effect of dietary inclusion of conjugated linoleic acid in finishing hog feed on sensory characteristics and storage quality indicators of pork loin" (2011). Graduate Theses,

Dissertations, and Problem Reports. 4748.

https://researchrepository.wvu.edu/etd/4748

This Thesis is protected by copyright and/or related rights. It has been brought to you by the The Research Repository @ WVU with permission from the rights-holder(s). You are free to use this Thesis in any way that is permitted by the copyright and related rights legislation that applies to your use. For other uses you must obtain permission from the rights-holder(s) directly, unless additional rights are indicated by a Creative Commons license in the record and/ or on the work itself. This Thesis has been accepted for inclusion in WVU Graduate Theses, Dissertations, and Problem Reports collection by an authorized administrator of The Research Repository @ WVU. For more information, please contact researchrepository@mail.wvu.edu. 
THE EFFECT OF DIETARY INCLUSION OF CONJUGATED LINOLEIC ACID IN FINISHING HOG FEED ON SENSORY CHARACTERISTICS AND

STORAGE QUALITY INDICATORS OF PORK LOIN

\author{
KAITLIN HOPE MADITZ
}

Thesis submitted to the

Davis College of Agriculture, Natural Resources, and Design

At West Virginia University

In partial fulfillment of the requirements

for the degree of

Master of Science

in

Animal \& Nutritional Sciences

with an emphasis in

Human Nutrition and Food

Kristen Matak, PhD., Chair

Kim Barnes, PhD.

Brett Kenney, PhD

Division of Animal \& Nutritional Sciences

Morgantown, West Virginia

2011 


\section{ABSTRACT \\ THE EFFECT OF DIETARY INCLUSION OF CONJUGATED LINOLEIC ACID IN FINISHING HOG FEED ON SENSORY CHARACTERISTICS AND STORAGE QUALITY INDICATORS OF PORK LOIN \\ KAITLIN HOPE MADITZ}

Marbling in meat occurs when fat is distributed throughout the skeletal muscle and is visually apparent by light streaks of fat that look like a marble pattern. It is associated with increased quality, tenderness, and likeability. Incorporating dietary conjugated linoleic acid (CLA) into finishing hog feed increases intramuscular fat and decrease backfat in harvested pigs; therefore, the purpose of this study was to determine if inclusion of CLA in pig feed would increase intramuscular marbling and consumer likeability without compromising storage stability. Twenty pigs were housed in ten pens ( 2 pigs per pen) and fed either $1 \%$ Soybean oil or $1 \%$ CLA diet for a period of six weeks. After slaughter, pork loins were cut and divided into cranial and caudal ends, vacuum packed and stored at $-8^{\circ} \mathrm{C}$ until evaluations were conducted. Quality indicators of pork were measured on both raw and cooked samples over a 7-d storage period.

Measurements included color $\left(\mathrm{L}^{*}, \mathrm{a}^{*}, \mathrm{~b}^{*}\right)$, muscle $\mathrm{pH}$, texture, and lipid oxidation by thiobarbituric acid reactive test (TBARS). Sensory panelists evaluated tenderness, juiciness, flavor, aroma, off-flavor, and likeability of each sample on an 8-point hedonic scale. Raw and cooked color scores, texture, TBARS, and raw and cooked muscle pH changed over time $(\mathrm{p}<0.05)$; however, these changes were independent of diet. Differences in quality indicators between diets were seen numerically but did not reach significance $(\mathrm{p}>0.05)$. Sensory evaluation by 20 panelists showed a trend that CLA loins presented with better flavor and juiciness $(\mathrm{p}<0.10)$; however, differences in sensory scores for all attributes failed to reach significance $(\mathrm{p}>0.05)$. Results of this study indicate that the inclusion of CLA in pig feed provides a meat product similar to soybean 
pig feed. The similar storage stability and sensory results of this study indicate limited, if any, benefits of feeding a CLA-diet over a traditional one.

Keywords: Linoleic acid; marbling; pork 


\section{ACKNOWLEDGEMENTS}

I would like to thank the faculty and staff in the Division of Animal and Nutritional Sciences at West Virginia University for this opportunity and their continued support throughout this project. I would like to thank Kristen Matak, Ph.D., my committee chair, for her expert guidance and availability to aid me during this academic endeavor. Thank you for lending words of encouragement and support during the times I needed it most. I would also like to thank my other committee members, Kim Barnes, Ph.D., and Brett Kenney, Ph.D., for their open door policy for questions and patience throughout my project.

Thank you Sarah Beamer for the countless hours you spent helping me with analyses, brainstorm ideas, and your willingness to answer phone calls at all hours of the day/night. The completion of this project would not have been possible without your guidance. I would like to thank John Burkhart for analyzing my data and helping me understand all of the results. I would also like to thank Jacek Jaczynski, Ph.D., Brett Kenney, Ph.D., Ken Blemmings, Ph.D., Susan Slider, and Tammy Webster for the use of their labs

Finally I would like to thank my friends and family members for their support. Thank you Helenia Sedoski and Brittney Pietrowski for your assistance on this project as well as the shared hours in the lab. Thank you to my mother and father for helping with various analyses and listening to my endless questions and complaints. Also, thank you to Leanne Boyd, my personal trainer, for keeping my stress to a minimum. Thank you lastly to my sister, Emily, for your continued support and kind words. 


\section{TABLE OF CONTENTS}

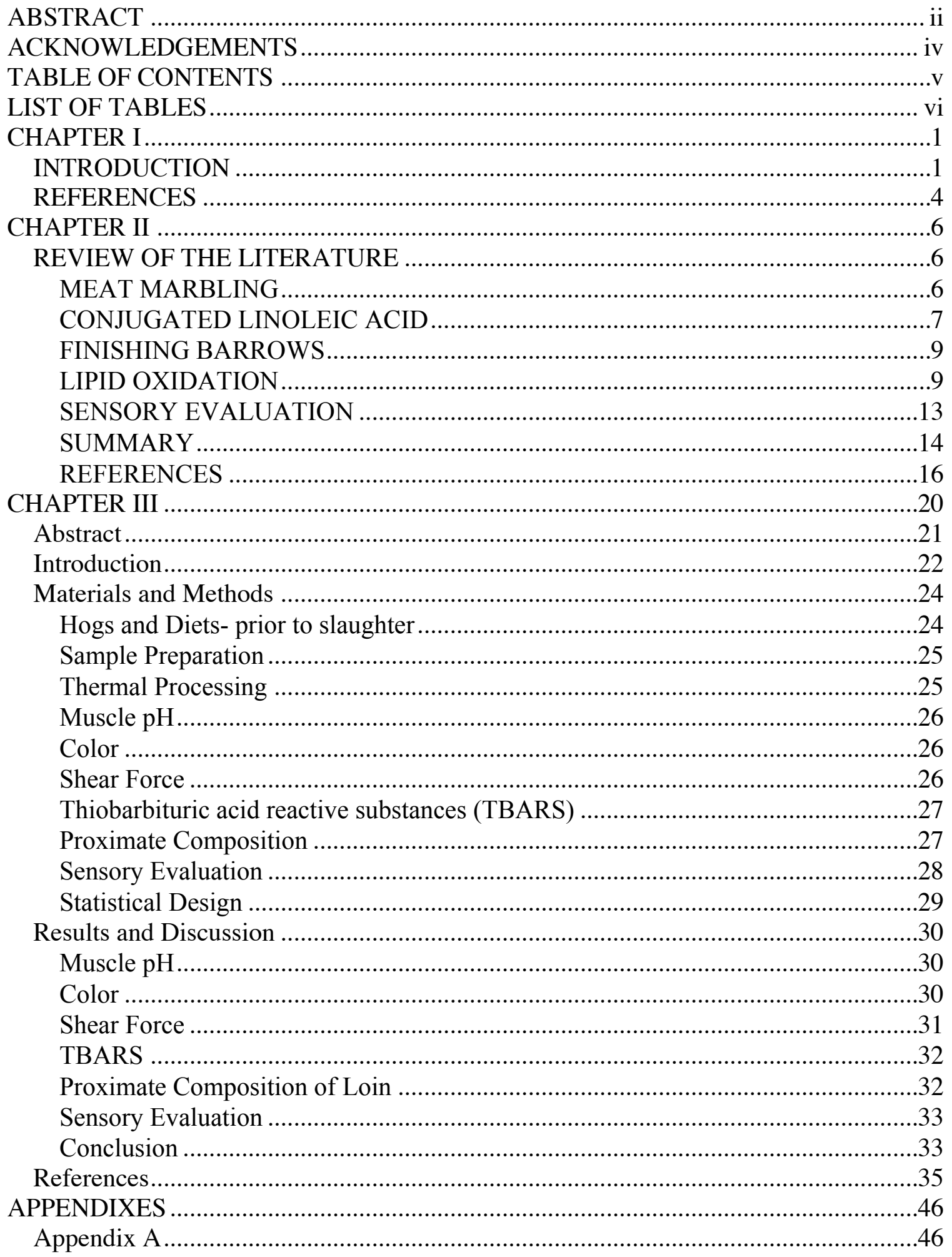




\section{LIST OF TABLES}

\section{CHAPTER III}

Table 1. Diet formulation calculated (as-fed basis) of diets shown below. Both control and CLA diets only differed in the $1.00 \%$ oil additive...

Table 2. Change in muscle $\mathrm{pH}$ of control and treatment (CLA) in both raw and cooked pork loin samples over a 7-d storage period. Although an interaction was seen over time $(\mathrm{p}<0.05)$, changes were independent of diet

Table 3. Raw color scores ( $\mathrm{L}^{*}, \mathrm{a}^{*}, \mathrm{~b}^{*}$ ) for control and treatment (CLA) pork loin samples over a 7-d storage time results are shown below. Time interactions $(\mathrm{p}<0.05)$ were independent of diet in regards to raw color scores...........................40

Table 4. Cooked color scores $\left(\mathrm{L}^{*}, \mathrm{a}^{*}, \mathrm{~b}^{*}\right)$ for control and treatment (CLA) pork loin samples over a $7 \mathrm{~d}$ storage time results are shown below. Time interactions $(\mathrm{p}<0.05)$ were independent of diet in regards to cooked color scores

Table 5. Textural analysis by Warner Bratzler sheer force, for the control and treatment (CLA) pork loin samples over a $7 \mathrm{~d}$ storage time. Day and diet interactions $(\mathrm{p}<0.05)$ were seen in the pork in regards to cooked texture scores........................42

Table 6. Lipid oxidation measured by thiobarbituric acid reactive substances test (TBARS) analyzed by dose: control and treatment (CLA) and by $7 \mathrm{~d}$ storage period. Color absorbance was read at $532 \mathrm{~nm}$ and TBARS values were reported as $\mathrm{mg}$ malondialdehyde (MDA) per kg sample. CLA samples had an overall decreased ( $\mathrm{p}<$ $0.05) \mathrm{mg}$ malondialdehyde (MDA); An interaction $(\mathrm{p}<0.05)$ between diet and day was also seen over the 7 -d storage period............................................ 43

Table 7. Proximate composition comparison of two diets: control diet (SBO) and conjugated linoleic acid (CLA). Proximate composition of ash, moisture, protein, and raw fat and the feeds were not significantly different $(\mathrm{P}>0.05)$. Significant differences $(\mathrm{p}<0.05)$ were seen between the cooked fat composition and diet..................44

Table 8. Sensory attributes representing flavor, juiciness, likeability, off flavor, and tenderness of the control and treatment (CLA) pork loin samples. No significant differences $(\mathrm{p}<0.05)$ were seen in any of the sensory attributes. 


\section{CHAPTER I}

\section{INTRODUCTION}

Marbling in meat occurs when fat is distributed throughout the skeletal muscle and is visually apparent by light streaks of fat that look like a marble pattern. Meat marbling can be more precisely defined as the intramuscular fat located in perimysial connective tissue between the muscle fiber bundles and is associated with increased quality, tenderness, and likeability (Aberle et al 2001). Oftentimes, in the pork industry, the presence of marbling is indicative of increased overall fat in the meat product. In response to the consumer demands for healthier meats containing less saturated fat, the

meat industry has produced hogs with lower hot carcass weights as well as less overall fat content. The production of leaner hogs drastically decreases the amount of marbling found in pork products, which could potentially decrease consumer likeability. Therefore, the meat industry is in search of a feeding approach that will produce meat with acceptable carcass compositions without compromising consumer satisfaction. By altering the location of fat distribution within meat from a subcutaneous depot to an intramuscular depot (marbling), the meat would comply with consumer demands without compromising quality standards.

Soybean oil is the typical dietary source of fat in hog feed; however, recent research has shown conjugated linoleic acid (CLA) to be a potential fat source (Dugan et al 2004; Weigand et al 2002; Larsen et al 2009). CLA is comprised of positional and geometric conjugated isomers of linoleic acid and has been shown to effect proliferation and differentiation of adipocytes (Jiang et al 2010). Although it would create a healthier 
meat product, inclusion of most unsaturated fatty acids in animal feed causes meat to be softer and less shelf-life stable due to fatty acid oxidation; however, CLA-also an unsaturated fatty acid- will improve growth rates of finishing hogs and increase the firmness of the meat (Wiegand et al., 2002; Larson et al., 2009). CLA has anticarcinogenic properties for humans and animals due to the furan fatty acids formed from the CLA autooxidation that can offer cell protection against various peroxides (Wiegand et al., 2002). This antioxidant effect provides further justification that the supplementation of CLA would have positive effects on fatty acid oxidation as well, which is an area of concern when supplementing other unsaturated fatty acids in the diet. The interaction between CLA and adipocyte formation provides evidence that supplementing this in animal feed might increase marbling and have positive effects on the overall pork product.

Hogs are monogastric animals and do not produce a great deal of CLA by bacterial biohydrogenation, making them possible candidates for receiving CLA in the diet. Dietary CLA will be deposited mostly within the hog tissue since it does not become saturated before absorption; therefore allowing the CLA to be bioavailable for human consumption (Dugan,M.E.R. 2004). In humans, CLA has shown to be an anticarcinogenic, antiatherogenic, and decrease risk for diabetes (Brandebourg et al 2005). CLA will reduce backfat and increase intramuscular fat which may have a positive effect on marbling (Wiegand, B.R. 2001; Wiegand,B.R. 2002).

Although the inclusion of CLA in hog feed shows potential, altering the fat additive may still negatively affect carcass quality, storage stability, and consumer likeability. Recent studies have shown CLA to increase the firmness of the pork as well 
as decrease backfat, but it is uncertain how this meat compares to a traditional soybean oil additive diet meat in regard to shelf life stability and consumer likeability (Wiegand, B.R. 2002). The oxidative stability of CLA-fed hogs compared to a traditional diet is hypothesized to improve, but it is unclear whether this would naturally create a greater storage stable product (Larsen,S.T. 2009). Also, the substitution of CLA for a regular soybean oil extract in hog feed may change the overall taste, tenderness, and juiciness of the pork product.

Creating a CLA-enhanced pork product that complies with health standards without compromising the quality or taste would be extremely beneficial to the meat industry. Although CLA has been shown to be a possible substitute for hog feed, few have researched the presence of marbling and various quality indicators associated with this alternative fat source; therefore, the aim of this study was to determine if the inclusion of CLA in pig feed would have an effect on intramuscular marbling and sensory characteristics while maintaining proper storage stability. 


\section{REFERENCES}

Aberle, E. D., Forrest, J. C., Gerrard, D. F., \& Mills, E. W. (2001). Principles of meat sicence (4th ed.). Dubuque, Iowa: Kendall Hunt Publishing.

Brandebourg, T.D., Hu, C.Y. 2005. Isomer-specific regulation of differentiating pig preadipocytes by conjugated linoleic acids. Journal of Animal Science. 83. 2096-2105.

Dugan, M. E. R., Kramer, J. K. G., \& Aalhus, J. L. (2004). Conjugated linoleic acid pork research. American Journal of Clinical Nutrition, 79(6), 1212s-1216s. 4

Jiang, Z. Y., Yang, L., Jiang, S. Q., Lin, Y. C., Zhong, W. J., \& Zheng, C. T. (2010). Conjugated linoleic acid differentially regulates fat deposition in backfat and longissimus muscle of finishing pigs. Journal of Animal Science, 88(5), 1694-1705.

Larsen, S. T., Swan, J. E., Sparks, J. C., Wiegand, B. R., \& Parrish, F. C. J. (2009). Dietary conjugated linoleic acid changes belly and bacon quality from pigs fed varied lipid sources. Journal of Animal Science, 87(1), 285-295.

Wiegand, B. R., Larsen, S. T., Baas, T. J., Parrish, F. C. J., \& Swan, J. E. (2001). Conjugated linoleic acid improves feed efficiency, decreases subcutaneous fat, and improves certain aspects of meat quality in stress-genotype pigs. Journal of Animal Science, 79(8), 2187-2195. 
Wiegand, B. R., Sparks, J. C., Parrish, F. C., Jr, \& Zimmerman, D. R. (2002). Duration of feeding conjugated linoleic acid influences growth performance, carcass traits, and meat quality of finishing barrows. [Duration of feeding conjugated linoleic acid influences growth performance, carcass traits, and meat quality of finishing barrows] Journal of Animal Science, 80, 637-643. 


\section{CHAPTER II}

\section{REVIEW OF THE LITERATURE}

\section{MEAT MARBLING}

The meat industry is always striving to create a meat product that will increase production performance as well as increase quality for consumers. In order to comply with consumer demands for healthier products containing less fat, the meat industry has produced leaner animals. The production of leaner animals has resulted in decreased intramuscular fat composition within the meat and compromised the meat quality in regards to taste, texture, and overall consumer approval (Fernandez et al 1999). Therefore, the meat industry is examining how to produce lean animals without sacrificing product quality. Selective lipid deposition is the current subject under investigation. Selective lipid deposition refers to altering the location of fat distribution on a cut of meat (Dodson et al 2010). By altering the fat location from subcutaneous fat to intramuscular fat (marbling), the meat would comply would contain less subcutaneous fat, more storage stability- through increased saturated fat, and still meet quality standards.

Meat marbling refers to the presence of fat within the perimysial connective tissue between muscle fiber bundles and is represented as light fat streaks arranged in a marbled pattern (Aberle 2001). Marbling is also associated with increased taste, tenderness, and consumer likeability (Aberle 2001). Due to the fat accumulating within the muscle instead of visceral or subcutaneous depots, the product is more lipid stable and has a higher quality. Marbling will increase as carcass weight increases; therefore, the presence of marbling has decreased with new consumer demands (Cannata et al 
2010). In order to increase marbling without increasing overall carcass weight, many mechanisms and feeding strategies that will alter adipocyte location are under review. Adipocyte differentiation is regulated by many transcription factors, and has recently been strongly linked to Peroxisome Proliferator-Activated Receptor (PPAR $\gamma$ ) expression (Wolins et al 2006). PPAR $\gamma$ is the main gene responsible for regulating the adipocyte specific genes and is required for adipose differentiation in mice (Rosen et al 1999). Although the complete mechanisms behind this gene expression regulator remain unknown, various ligands (such as conjugated linoleic acid) have shown to decrease the activity of this gene, decrease subcutaneous preadipocyte formation, and increase intramuscular preadipocyte formation - marbling (Kang et al 2003; Zhou et al 2007).

\section{CONJUGATED LINOLEIC ACID}

Conjugated linoleic acid (CLA) is comprised of positional and geometric conjugated isomers of linoleic acid (18:2n-6) and has been shown affect proliferation and differentiation of adipocytes (Jiang et al 2010). Researchers found that when given to rats, CLA successfully decreased body fat and increased overall body growth and lean mass amount (Dugan 2004). High levels of CLA are found in ruminant animals (beef, dairy cows) and dairy products (cheese, milk-fat), while lower levels of CLA can be found in fish, plant products, and pigs (monogastric) (Kent 2007).

CLA are naturally occurring linoleic acid isomers (cis-9,trans-11-CLA) produced as an intermediate during biohydrogenation of linoleic acid in the ruminant gut (Brandebourg et al 2005; Khanal et al 2004). The cis-9,trans-11-CLA is then either absorbed into the meat tissue or further metabolized- hydrogenated at position 9 where it is turned into vaccenic acid (trans-11-octadecenoic). After being absorbed into the 
tissues, the delta 9 desaturase enzyme converts the vaccenic acid back into the cis9,trans-11-CLA form (Kent 2007; Pariza, Park, Cook 2001). Recently, there has been interest in the commercially prepared trans- 10 , cis- 12 formation of CLA. This isomer has been shown to affect lipid differentiation. Due to the synergistic action (body fat and anti-carcinogenic) associated with the different forms of the isomers as well as the increased cost associated with the trans-10, cis-12 isomer, normally a combination of forms is used (Kent 2007).

CLA is known to have anticarcinogenic, antidiabetic, and altered lipid differentiation when supplemented in mammals (Brandebourg et al 2005). The recent FDA allowance of 60\% CLA isomers (BASF) within the fat additve of animal diets (making the CLA $0.6 \%$ of the entire diet) has permitted the meat industry to examine the potential benefits to CLA supplementation. Supplementing cis-9,trans-11:trans-10,cis-12 CLA isomers is known to target adipocyte differentiation and create a product with increased intramuscular fat percentages (Kang et al 2003; Zhou et al 2007). These findings can be explained by the role of CLA acting as a direct ligand of PPAR $\gamma$, mentioned above. The greatest negative implication associated with CLA supplementation within the meat industry is increased cost. In order to see the beneficial results associated with CLA supplementation and meat quality, appropriate amounts 0.5$1.5 \%$ CLA must be added to the diet, which will inevitably increase production costs (Dugan et al 2004). 


\section{FINISHING BARROWS}

The interest in CLA supplementation in pig feed has increased over the past decade due to the possible carcass quality and meat trait improvement (Marco et al 2009). The potential for CLA to be included in hog diets and improve meat quality is related to altered lipid metabolism that occurs in monogastric animals. The decreased production of gut microorganisms compared to ruminants as well as the increased rate of stomach passage, decreases the amount of CLA produced during gastric hydrogenation within hogs (Dugan et al 2004). The increased rate of stomach passage and reduced gut bacteria allow the CLA to be deposited in the saturated form in hogs (Dugan et al 2004). Due to the decreased CLA saturation before absorption in hogs, supplemented dietary CLA remains deposited within the pork tissue and can provide a significant source of CLA for consumers (Dugan et al 2004).

The inclusion of CLA has been shown to improve growth rates of finishing hogs and increase the firmness of the meat (Wiegand et al 2002; Larson et al 2009). CLA was also found to regulate fat deposition (through PPAR $\gamma$ gene expression) when supplemented in finishing pig feed (Jiang et al 2010). Although CLA was found to reduce backfat and increase intramuscular fat in hogs, it is unclear if the CLA supplemented pork is similar to a traditionally fed product in regards to taste, texture, and oxidation (Wiegand 2001; Wiegand 2002).

\section{LIPID OXIDATION}

Within the meat industry, it is known that the presence of off-flavors and off aromas can be attributed mostly to lipid peroxidation (Wang et al 2002). As the lipids within the meat product degrade, the product becomes more rancid and less acceptable for consumers. When examining the inclusion of dietary CLA in pig feed, the most 
common concern is the associated oxidative and storage stability compared to a traditional pig feed. In addition to the natural microbial/physical changes in pork that occur over storage time, fatty acid oxidation will increase as the unsaturated fat concentration within the cut of meat increases, which can further decrease shelf-life stability.

The inclusion of most unsaturated fatty acids in finishing hog feed causes meat to be softer and less shelf-life stable due to fatty acid oxidation; however, CLA has been shown to increase the firmness of the meat (Wiegand et al 2002; Larson et al 2009). The CLA autooxidation, from the formation of furan fatty acids (derived from furans containing either a propyl or pentyl side chain in the alpha position), offers extended cell protection against various peroxides (Wiegand et al 2002; Spiteller 2005), which could also have positive effects on shelf-life stability and fatty acid oxidation. Although many have hypothesized a decrease in oxidation and an increase in storage quality, the full effects of CLA supplementation in regards to oxidation and storage quality parameters remain unknown (Wiegand et al 2001). The measurement of TBARS, color, texture, and $\mathrm{pH}$, remain the best analyses to determine oxidative and shelf life stability.

Lipid oxidation. Thiobarbituric Acid Reactive Substances (TBARS) is the most acceptable analysis to determine the lipid oxidation within a cooked meat sample (Aberle et al 2001). Compared to other methods, TBARS is the best method for qualitycontrolled results when testing a large amount of samples (Wang et al 2002). In this analysis, the thiobarbituric acid (TBA) reacts with malondialdehyde to provide an estimation of the oxidation present (Wang et al 2002). Malondialdehyde (MDA), the secondary product of lipid peroxidation, is formed during the decomposition of unstable 
lipid peroxides in conjunction with a series of other compounds (Spanier and Traylor 1991). The presence of MDA generates a red coloration and can then be detected using a spectrophometer (Wang et al 2002). The acceptable mg MDA/kg product threshold values for meat are between $0.5-1.0 \mathrm{mg}$ MDA; Values higher than this indicate product rancidity (Wiegand et al 2002).

In a study conducted by Wiegand and others (2002), CLA supplemented barrows resulted in an overall decrease in mg MDA production $(\mathrm{p}<0.05)$ compared to traditionally fed barrows over a shelf life period. The decrease in MDA from the CLA pigs was suggested to be due to the reduced amount of unsaturated fatty acids present in the supplemented barrows. Although unsaturated fatty acids are normally known to be more prone to attacks by free radicals due to the double bond placement, CLA proved to negate this claim (Wiegand et al 2002).

Similar results were seen by Martin and others (2008) and Marco and others (2009) with the increased addition of CLA on a dry- cured pork loin and breakfast sausages respectively. The higher the content of CLA incorporated into the meat, the lower the mg MDA reported for each of the samples. The researchers of these studies also concluded that CLA inclusion on dry-cured loins and breakfast sausages produced more oxidative stability than the traditionally fed meat (Martin et al 2008, Marco et al 2009).

Color. Loin muscle color provides a direct indication of overall pork quality as well as spoilage. Consumers determine the freshness and quality of the loin by viewing the amount of discoloration present. The measurement of color via a colorimeter is widely used method to determine the presence or absence of meat rancidity (Dugan et al 
2004). Using the Hunt color system, denaturation of the myoglobin (indicates pork quality), the main protein responsible for protein color, is displayed as an increase in the $\mathrm{L}^{*}$ value (lightness), and decrease in both the $\mathrm{a}^{*}$ value (redness) and the $\mathrm{b} *$ value (yellowness) within the muscle (Mancini et al 2006).

Research conducted by Thiel and others (1998) and Wiegand and others (2002) indicates that CLA supplemented pork reacts similarly to traditional feed pork. Although findings by Thiel and others (1998) suggest that increases in CLA amounts increase $\mathrm{a}^{*}$ redness amounts which could show a protection of meat color. In contrast, Wiegand and others (2002) found similar a* among the CLA and control pork. Recent research indicates that although the $\mathrm{L}^{*}$ and $\mathrm{a}^{*}$ are not greatly affected by the CLA inclusion, $\mathrm{b}^{*}$ values seem to increase-showing a more yellowed, less acceptable meat product (Wiegand et al 2002).

$p H$. Another strong marker of pork quality is muscle $\mathrm{pH}$ measurement. The initial muscle $\mathrm{pH}$ measurement is a reflection of slaughter procedures, and as the meat becomes more rancid and conducive to microbiological instability, the $\mathrm{pH}$ rises (Holmer et al 2009); therefore making $\mathrm{pH}$ a good measurement to indicate oxidation. Although there are many ways to measure $\mathrm{pH}$ in meat, the most reliable and easiest remains to be using a surface $\mathrm{pH}$ probe (Serra et al 1998). The acceptable $\mathrm{pH}$ value for a pork product is within the range of 5.4-6.5 (Wiegand et al 2002).

Although many have looked at the $\mathrm{pH}$ changes associated with CLA enhanced meat products, conflicting data has been reported (Dugan et al 2004). In a study conducted by D'Souza and Mullan (2002) CLA pork resulted in increased pH values over time, therefore showing increased oxidation. However, several similar studies indicate 
there is no change in $\mathrm{pH}$ over time associated with the supplementation of CLA in pork (Joo et al 2002; Wiegand et al 2001; Wiegand et al 2002). The effect of CLA supplementation on the $\mathrm{pH}$ of pork over time has not been reported.

\section{SENSORY EVALUATION}

When conducting a sensory evaluation of a pork product, there are several things that must be controlled to ensure the measurements are accurate and representative of how consumers will react to the sampled product. All samples must be cooked (addition of water only) at the same temperature (internally $70^{\circ} \mathrm{C}$ ), be of uniform size $(2.54 \mathrm{~cm})$, and be arranged in a randomized pattern regardless of the investigated parameter (American Meat Science Association 1995).

It is also important that there is consistency among the panelists and their knowledge of the sensory evaluation process (Aberle et al 2001; American Meat Science Association 1995). The sensory evaluation of meat should be conducted with each parameter on an 8 - point hedonic scale; appropriate parameters include taste, texture, juiciness, off-flavor, associated aftertaste, likeability and aroma. Participating panelists should be given proper pallet cleansing agents and be free from sensory fatigue (American Meat Science Association 1995).

With pork sensory evaluation, the most common parameter tested is texture/tenderness. Although this test is also conducted using the Warner-Bratzler sheer force measurement on a Texture Analyzer, it is beneficial to perform the instrumental analysis in conjunction with a sensory evaluation (Aberle et al 2001). Sensory evaluation 
research of CLA supplemented pork indicates similar tenderness scores compared to the control (Wiegand et al 2002; Dugan et al 1999).

The effects of CLA supplementation on pork loins and sensory characteristics are not fully understood (Weigand et al 2002). Other tested parameters such as juiciness, flavor, and off flavors indicate no difference in CLA supplemented and traditional diet fed pork (Dugan et al 1999). Although the inclusion of CLA in hog feed increases marbling, it may also produce off-flavors, off- odors, and overall decreased consumer likeability (Dugan et al 2004; Janz et al 2008). According to Corino and others, (2003) minimal effects were seen in regard to sensory quality on CLA supplemented dry-cured hams; however, in a study examining the sensory effects of CLA supplementation on longissmus muscle portion of the loin, off-odors were noted by the panelists (Janz et al 2008). The potential for off-odors, off-flavors, and decreased tenderness from increased oxidation within the CLA supplemented pork loin leaves the pork industry cautious about introducing CLA enhancement as common practice.

\section{SUMMARY}

With the potential for inclusion of CLA within the diet, numerous questions and concerns arise in regards to meat firmness, lipid oxidation, color, and consumer likeability. Although the inclusion of CLA has been reported to successfully alter adipocyte deposition, research conducted on sensory evaluation and quality indicators has provided conflicting data. Sensory reports indicate that CLA inclusion may promote offflavors and off-odors while instrumental reports show a possibility for decreased storage stability. Due to the increased cost associated with CLA supplementation for the meat 
industry, it is necessary to examine if this feeding strategy should be implemented. This study aimed at determining the effect of CLA inclusion on pork sensory characteristics and storage quality indicators by measuring sensory parameters, TBARS, color, $\mathrm{pH}$, and texture over a $7 \mathrm{~d}$ storage period. 


\section{REFERENCES}

Aberle, E. D., Forrest, J. C., Gerrard, D. F., \& Mills, E. W. (2001). Principles of meat sicence (4th ed.). Dubuque, Iowa: Kendall Hunt Publishing.

American Meat Science Association. (1995). In National Live Stock and Meat Board, American Meat Science Association (Ed.), Research guidelines for cookery, sensory evaluation and instrumental tenderness measurements of fresh meat. Chicago, Illinois: American Meat Science Association.

Cannata, S., Engle, T.E., Moeller, S.J., Zerby, H.N., Radunz, A.E., Green, M.D., Bass, P.D., Belk, K.E. 2010. Effect of visual marbling on sensory properties and quality traits of pork loin. Journal of Meat Science. 85:3. 428-434.

Corino, C., Magni, S., Pastorelli, G., Rossi, R., Mourot, J. 2003. Effect of conjugated linoleic acid on meat quality, lipid metabolism, and sensory characteristics of dry-cured hams from heavy pigs. Journal of Animal Science. 81(9), 2219-2229.

Fernandez, X., Monina, G., Talmanta, A., Mouroth, J., and Lebret, B. 1999. Influence of intramuscular fat content on the quality of pig meat - 1 . Composition of the lipid fraction and sensory characteristics of $\mathrm{m}$. longissimus lumborum. Journal of Meat Science. 53(1), 59-65. 
Dugan, M. E. R., Kramer, J. K. G., \& Aalhus, J. L. (2004). Conjugated linoleic acid pork research. American Journal of Clinical Nutrition, 79(6), 1212s-1216s. 4

Janz, J.A., Morel, P.C., Purchas, R.W., Corrigan, V.K., Cumarasamy, S., Wilkinson, B.H., Hendriks, W.H. 2008. The influence of diets supplemented with conjugated linoleic acid, selenium, and vitamin E, with or without animal protein, on the quality of pork from female pigs. Journal of Animal Science. 88(6), 1402-1409.

Jiang, Z. Y., Yang, L., Jiang, S. Q., Lin, Y. C., Zhong, W. J., \& Zheng, C. T. (2010). Conjugated linoleic acid differentially regulates fat deposition in backfat and longissimus muscle of finishing pigs. Journal of Animal Science, 88(5), 1694-1705.

Larsen, S. T., Swan, J. E., Sparks, J. C., Wiegand, B. R., \& Parrish, F. C. J. (2009). Dietary conjugated linoleic acid changes belly and bacon quality from pigs fed varied lipid sources. Journal of Animal Science, 87(1), 285-295.

Mancini, R.A., Hunt, M.C. 2005. Current research in meat color. Journal of Meat Science. 71:100. 121.

Martin, D., Antequera, T., Muriel, E., Palacios, T.P., Ruiz, J. 2008. Effect of dietary conjugated linoleic acid in combination with monounsaturated fatty acids on the meat composition and quality traits of dry-cured loin. Journal of Meat Science. 80:4. 13091319. 
Moya-Camarena, S. Y., Vanden-Heuvl, J.P., Blachard, S.G., Leesnitzer, L.A., Belury, M.A. (1999). Conjugated Linoleic Acid is a potent naturally occurring ligand and activator of PPAR. Journal of Lipid Research. 40. 1426-1433.

Serra, X., Gil, F., Pérez-Enciso, M., Oliver, M.A., Vázquez, J.M., Gispert, M., Díaz, I., Moreno, F., Latorre, R., Noguera, J.L. 1998. A comparison of carcass, meat quality and histochemical characteristics of Iberian (Guadyerbas line) and Landrace pigs. Journal of Livestock Production Science. 56:3. 215-223.

Spanier, A.M., Traylor, R.D. 1991. A rapid, direct chemical assay for the quantitative determination of thiobarbituric acid reactive substances in raw, cooked, and cooked/stored muscle foods. Journal of Muscle Foods. 2. 165-176.

Spiteller, G. 2005. Furan fatty acids: occurrence, synthesis, and reactions. Are furan fatty acids responsible for the cardioprotective effects of a fish diet? Journal of Lipids. 40(8), $755-771$.

Thiel, R.L., Sparks, J.C., Wiegand, B.R., Parrish, F.C., Evan, R.C. 1998. Conjugated linoleic acid improves performance and body composition in swine. Journal of Animal Science. 76:57.

Wiegand, B. R., Larsen, S. T., Baas, T. J., Parrish, F. C. J., \& Swan, J. E. (2001). Conjugated linoleic acid improves feed efficiency, decreases subcutaneous fat, and 
improves certain aspects of meat quality in stress-genotype pigs. Journal of Animal Science, 79(8), 2187-2195.

Wiegand, B. R., Sparks, J. C., Parrish, F. C., Jr, \& Zimmerman, D. R. (2002). Duration of feeding conjugated linoleic acid influences growth performance, carcass traits, and meat quality of finishing barrows. [Duration of feeding conjugated linoleic acid influences growth performance, carcass traits, and meat quality of finishing barrows] Journal of Animal Science, 80, 637-643.

Wolins N.E., B.K. Quaynor, J.R. Skinner, A. Tzekov, C. Park, K. Choi, P.E. Bickel. 2006. OP9 mouse stromal cells rapidly differentiate into adipocytes: characterization of useful new model of adipogenesis. Journal of Lipid Research 47, 450-460. 


\section{CHAPTER III}

THE EFFECT OF DIETARY INCLUSION OF CONJUGATED LINOLEIC ACID IN FINISHING HOG FEED ON SENSORY CHARACTERISTICS AND STORAGE QUALITY INDICATORS OF PORK LOIN 


\begin{abstract}
The effect of conjugated linoleic acid (60\% CLA Isomer; 50:50 c9,t11:t

$10, \mathrm{c} 12$; BASF) as a fat source for hog feed 42 days prior to slaughter on marbling, sensory characteristics, and storage stability was examined. Twenty barrows (PIC $380 \mathrm{x}$ Cambrough 1025) were randomly paired, housed in ten pens, and fed either $1 \%$ Soybean oil or 1\% CLA diet for a period of six weeks. Quality indicators of pork were measured on both raw and cooked samples over a 7-d storage period. Measurements included color $\left(\mathrm{L}^{*}, \mathrm{a}^{*}, \mathrm{~b}^{*}\right)$, muscle $\mathrm{pH}$, texture, proximate composition, and lipid oxidation by thiobarbituric acid reactive test (TBARS). Sensory panelists evaluated tenderness, juiciness, flavor, aroma, off-flavor, and likeability of each sample on an 8-point hedonic scale. Raw and cooked color scores, texture, TBARS, and raw and cooked muscle pH changed over time $(\mathrm{p}<0.05)$; independent of diet. Sensory evaluation showed a trend that CLA loins presented with better flavor and juiciness $(\mathrm{p}<0.10)$. The similar storage stability and sensory results indicate limited, if any, benefits of feeding a CLA-diet over a traditional one.
\end{abstract}




\section{Introduction}

In order to comply with consumer demands for healthier pork products containing less fat, the meat industry has produced leaner hogs. This production of leaner hogs has decreased fat composition within the meat and compromised the meat quality in regards to taste, texture, and overall consumer approval (Fernandez et al 1999). Therefore, the meat industry is examining how to raise lean hogs without sacrificing product quality. By altering the fat location from subcutaneous fat to intramuscular fat (marbling), the pork would comply with consumer demands for a lower-fat product and still meet quality standards (Dodson et al 2010).

In an effort to improve pork quality, the inclusion of many natural feed additives within the finishing hog diet has been examined; including conjugated linoleic acids (CLA). CLA is comprised of positional and geometric conjugated isomers of linoleic acid and has been shown to effect proliferation and differentiation of adipocytes (Jiang et al 2010). CLA may also be a ligand and activator of the major adipocyte transcription factor Peroxisome Proliferator-Activated Receptor (PPAR $\gamma$ ) which allows the CLA to alter the fat depot from subcutaneous to intramuscular and possibly increase marbling (Moya-Camarena et al 1999).

Although the inclusion of CLA increases the amount of saturated fat concentration within the pork, which is known to be less prone to oxidation, it may also produce off-flavors, off- odors, and overall decreased consumer likeability (Dugan et al 2004; Janz et al 2008). The effects of CLA supplementation on pork loins and sensory characteristics are not fully understood (Weigand et al 2002). According to Corino and others, (2003) minimal effects were seen in regard to sensory quality on CLA 
supplemented dry-cured hams; however, in a study examining the sensory effects of CLA supplementation on longissmus muscle portion of the loin, off-odors were noted by the panelists (Janz et al 2008). The potential for off-odors, off-flavors, and decreased tenderness within the CLA supplemented pork loin leaves the pork industry cautious about introducing CLA enhancement as common practice.

In addition to the natural microbial/physical changes in pork that occur over storage time, fatty acid oxidation will increase as the unsaturated fat concentration within the cut of meat increases, which can further decrease shelf-life stability. The inclusion of most unsaturated fatty acids in finishing hog feed causes meat to be softer and less shelflife stable due to fatty acid oxidation; however, CLA has been shown to improve growth rates of finishing hogs and increase the firmness of the meat (Wiegand et al 2002; Larson et al 2009). The CLA autooxidation, from the formation of furan fatty acids (derived from furans containing either a propyl or pentyl side chain in the alpha position), offers extended cell protection against various peroxides (Wiegand et al 2002; Spiteller 2005), which could also have positive effects of shelf-life stability and fatty acid oxidation. Although many have hypothesized the potential for this feed source, the full effects of CLA supplementation in regards to color, texture, $\mathrm{pH}$, and storage stability remains unknown.

The inclusion of CLA in hog feed may offer several beneficial effects such as increased marbling, increased intramuscular saturated fat, and increased feed efficiency for farmers; however, the storage stability, quality parameters, and consumer likeability may be compromised. Therefore, the aim of this study was to determine if the inclusion 
of CLA in pig feed would have an effect on intramuscular marbling and sensory characteristics while still ensuring proper storage stability.

\section{Materials and Methods}

\section{Hogs and Diets- prior to slaughter}

This project was conducted in accordance with West Virginia University Animal Care and Use Committee Guidelines. Twenty barrows (PIC 380 x Cambrough 1025) average starting weight $53 \mathrm{~kg} \pm \mathrm{SD}$ were housed at the WVU farm for the duration of this study. The barrows were randomly assigned to two treatment groups and housed in ten pens, two pigs per pen (with "pen" as the experimental unit). Pigs were given commercial corn-based feed with a SBO fat additive, the feeding study control, ad libitum and full excess to water for a 12 week adjustment period before the feeding study began.

Treatment groups included a control diet (soybean oil; SBO) or treatment (CLA) group. A commercial preparation of 60\% CLA isomers (50:50 c9,t11:t10,c12; provided by BASF) replaced the SBO and was included in the commercial diet at $1.00 \%$. Diet formulation of the feed was consistent (Table 1). Pigs were allowed ad-libitum access to feed and water for six weeks prior to slaughter, and were weighed weekly to monitor growth. Average daily gain, average daily feed intake, and gain:feed were all measured and exhibited no differences between control and treatment barrows. Following the sixweek feeding study, all pigs were slaughtered at a commercial facility. Hot carcass weights were then measured $(81.4 \mathrm{~kg} \pm 4.97)$ and meat was chilled in a slaughterhouse 
for $24 \mathrm{~h}$. Pork loins were removed after slaughter, deboned, and cut at the WVU meat laboratory.

Pork chops located at T-10 and T-11 were collected for marbling scores and fatty acid testing, while the remainder of the loin (beginning with T-3) was divided into cranial and caudal ends, immediately placed into non-permeable gas bags, vacuum sealed, and stored in a non-oxidative $-20^{\circ} \mathrm{C}$ walk-in freezer. After $24 \mathrm{~h}$, the loins were cut while frozen into $2.54 \mathrm{~cm}$ thick pork chops with a meat-cutting saw to ensure uniform chop thickness. Pork chops were repackaged, randomly assigned to sensory and lab analyses and stored at $-20^{\circ} \mathrm{C}$ until analyses were conducted to minimize any change in loin quality over time (Hanson, 2004).

\section{Sample Preparation}

Prior to all analyses, designated pork chops were removed from the freezer, placed in a $4^{\circ} \mathrm{C}$ food-grade low temperature refrigerator for 14 days to simulate retail aging. Pork chops remained in the vacuum seal packaging during the aging process, and were then placed on Styrofoam trays and refrigerated for a maximum of $7 \mathrm{~d}$. Sensory analyses were performed on day 1 (Styrofoam tray) and shelf life analyses were performed on days $1,3,5$, and 7 .

\section{Thermal Processing}

Pork chops were cooked prior to sensory evaluation and quality indicator testing.

Chops used for the sensory analysis were cooked on day 1 after thawing; chops for laboratory evaluations were thawed and cooked on days 1,3,5 and 7. Full chops were placed in individual 9-in rectangular pans and cooked in $118 \mathrm{ml}$ water. Chops used for laboratory testing were cut into four $2.54 \mathrm{~cm}$ quadrants and cooked individually at days 1 , 
3, 5, and 7 in 9-in rectangular pans with $118 \mathrm{ml}$ water. All chops were cooked at $165^{\circ} \mathrm{C}$ for approximately $45 \mathrm{~min}$ or until reaching an internal temperature of at least $70^{\circ} \mathrm{C}$. A Beckman Industrial Data logger (Model 205; Beckman Instruments, Fullerton, CA) was used to monitor internal chop temperatures during the cooking process; thermometer probes were placed in the center of the chops.

\section{Storage Study}

\section{Muscle pH}

Muscle $\mathrm{pH}$ was assessed on days 1,3,5, and 7 prior to and after cooking to determine initial muscle $\mathrm{pH}$ and if loin degradation occurred over time. Each chop was divided into four quadrants; $\mathrm{pH}$ assessments were taken at the center portion of each quadrant by surface penetration of a pH probe (Model 350, Corning Inc.; Corning NY, USA) to ensure minimal disturbance to muscle and receive an accurate reading. Measurements were taken in triplicate directly prior to cooking and directly after cooking.

\section{Color}

Meat color was measured at days 1,3,5, and 7 using a standard chromameter (Model CR-300; Minolta Camera Co. Ltd., Osaka Japan.) Evaluations were conducted at the center of each chop quadrant prior to and after cooking. The chromameter provided three measurements on each meat sample: lightness ( $\mathrm{L}^{*}$-scale: $\left.0-100\right)$, yellowness (showing muscle degradation)- ( $\mathrm{b}^{*}$-scale: $\left.-60-+60\right)$, and redness ( $\mathrm{a}^{*}$ - scale: $\left.-60-+60\right)$.

\section{Shear Force}

Shear force was conducted on cooked samples for shelf life on days 1,3,5, and 7. A core of the sample was created for this test using a uniform coring instrument. After 
cooking, chop quadrants were cored and measured for shear force. The Warner-Bratzler attachment on the Texture analyzer (Model TA-HDi) was used to determine the peak force needed to shear one core sample - thus measuring the tenderness of the meat. The texture analyzer parameters were as follows: pre-test speed - $2 \mathrm{~mm} / \mathrm{sec}$; test speed $5 \mathrm{~mm} / \mathrm{sec}$; post test speed $-5 \mathrm{~mm} / \mathrm{sec}$; distance $-25 \mathrm{~mm} / \mathrm{sec}$; force $-100 \mathrm{~g}$; time $-5 \mathrm{sec}$; load cell $-50 \mathrm{~kg}$.

\section{Thiobarbituric acid reactive substances (TBARS)}

Lipid oxidation of pork loin was measured by the thiobarbituric acid reactive substances (TBARS) test. Samples were measured in triplicate for lipid oxidation after cooking on days 1, 3, 5, and 7 using the methods described by Yu and Sinnhuber (1957). The color absorbance was read at $535 \mathrm{~nm}$ and the measurement was calculated based on a standard curve.

\section{Proximate Composition}

Percent fat, moisture, protein, and ash was determined on each raw meat sample according to the AOAC approved methods.

Fat content in chops was measured in accordance with the Soxhlet extraction method. Each sample size was weighed at $1-1.5 \mathrm{~g}$ while extraction time remained constant at 18-24 hours with a drip rate of 200 drips per minute. Petroleum ether was used to complete all extractions.

Moisture content was measured by placing samples, weighing $4.5-5 \mathrm{~g}$, in a $70^{\circ} \mathrm{C}$ oven and dried to a constant weight for 16 hours at a partial vacuum pressure of $20 \mathrm{~mm}$ Hg. After drying, samples were placed in a desiccator, cooled properly, and weighed. 
Percent moisture of the samples was calculated using the following equation (AOAC 925.09): \% Moisture $=[$ sample weight $(\mathrm{g})-$ dry weight $(\mathrm{g}) /$ sample weight $(\mathrm{g})] * 100$.

Ash content was measured by weighing 2-3g of sample in a crucible and placing in a muffle furnace at $525^{\circ} \mathrm{C}$ until the presence of light gray ash appeared. Samples were cooled in a desiccator and weighed. Percent ash of samples was calculated using the following equation $(\mathrm{AOAC} 932.03): \%$ Ash $=$ [weight of ash $(\mathrm{g}) /$ weight of original sample $(\mathrm{g})] * 100$.

Crude protein was measured with the Kjeldahl method. Samples were weighed at $0.25 \mathrm{~g}$, folded into Whatman \#1 paper, and placed in Kjeldahl tubes. A Kjeltab and 10mL of sulfuric acid was added to each tubes. Samples were digested with maximum airflow for 5-10 minutes at $420^{\circ} \mathrm{C}$. After reducing the airflow, samples were further digested for 40-45minutes. Tubes were then added with distilled water $(75 \mathrm{~mL})$ and placed in a Kjeltec 1030 Auto Analyzer. Crude protein of the samples was calculated using the following equations:

$\%$ Nitrogen $=(\mathrm{mL}$ acid titrated $*$ normality of $\mathrm{HCl} * 14.01) /[(\mathrm{a} * \% \mathrm{DM}) * 10)]$ $\%$ Crude protein $=\%$ Nitrogen $* 6.25$

\section{Sensory Evaluation}

Following cooking, samples were cut from a template into uniform $2.54 \mathrm{~cm}$ cubes, placed in 2-oz plastic cups, assigned a random 3-digit code, covered with plastic lids, and stored in a warming oven at $65^{\circ} \mathrm{C}$ until sensory evaluations were conducted $(<1$ h).

A panel of 22 people over the age of 18 was used for the sensory testing in this study. The number of panelists was limited due to the amount of product sample 
available for tasting. Each panelist participated in two tasting sessions, each lasting 30 $\min$. The tasting sessions were conducted on the same day and were $3 \mathrm{~h}$ apart. Testing was conducted by the methods described by the National Pork Board (American Meat Science Association, 1995).

At each session, panelists were presented with five sets of two samples in randomized complete block design for evaluation. Each set of samples was presented at least $5 \mathrm{~min}$ apart from the previous set. Room temperature water and unsalted crackers were provided to panelists to cleanse their pallet between samples. An 8-point hedonic scale was used to evaluate the samples where $1=$ least presence of attribute and $8=$ greatest presence of attribute. Panelists were asked to evaluate each sample for tenderness, juiciness, flavor, aroma, off flavor, and likeability of each sample.

\section{Statistical Design}

The response variables for the storage study including $\mathrm{pH}$, color, texture, TBARS were all completed in triplicate. Proximate composition (moisture, ash, protein, and total fat), TBARS, $\mathrm{pH}$, color, and texture analyses results were generated by taking 2 measurements per sample ( 2 measurements from each pig for all analyses). A $2 \times 4$ factorial experimental design with complete randomization was applied and the data were analyzed using ANOVA where the two factors were Time with levels 1,3,5, and 7 days and pork loin type with levels control and CLA (treatment). The relationship between surface $\mathrm{pH}$, color, texture, and TBARS and time was analyzed using simple linear regression. To analyze mean separation, Tukey's Honestly Significant Differences Test $(p<0.05)$ was performed for all analyses including sensory measurements. All statistical 
analyses listed above were completed using JMP 8 software (SAS Institute, Cary, NC, USA).

\section{Results and Discussion}

\section{Shelf-life study}

\section{Muscle pH}

Values for raw and cooked $\mathrm{pH}$ over storage time are presented in Table 2. The initial muscle $\mathrm{pH}$ measurement is a reflection of slaughter procedures, and as the meat becomes more rancid and conducive to microbiological instability, the $\mathrm{pH}$ rises (Holmer et al 2009). An interaction was seen for raw and cooked $\mathrm{pH}$ over time $(\mathrm{p}<0.05)$, but the changes were independent of diet. For the control and treatment groups means ranged from 5.676 to 6.593 and all values were considered within acceptable pork $\mathrm{pH}$ ranges (Bendall et al 1989). Both the cooked/raw CLA and the control group pork showed an increase in muscle $\mathrm{pH}$ between days 3,5 , and $7(\mathrm{p}<0.05)$. The elevation of $\mathrm{pH}$ over storage time showed the natural spoiling effect that occurs within meat muscle. The similar trends for $\mathrm{pH}$ regardless of diet show that CLA supplemented pork is comparable to traditionally diet fed pork.

\section{Color}

Loin muscle color provides a direct indication of overall pork quality as well as spoilage. Consumers evaluate the freshness and muscle quality of the loin by viewing the amount of discoloration present. The denaturation of the myoglobin (indicates pork quality), the main protein responsible for protein color, is displayed as an increase in the $\mathrm{L}^{*}$ value (lightness), decrease in both the $\mathrm{a}^{*}$ value (redness) and the $\mathrm{b}^{*}$ value 
(yellowness) within the muscle via colorimeter measurements (Mancini et al 2005). The Hunter Color system was used to determine the loin muscle color on the raw and cooked samples over time. Results of the raw and cooked measurements by $\mathrm{L}^{*}, \mathrm{a}^{*}, \mathrm{~b}^{*}$ are listed in Table 3 and Table 4. A significant decrease $(\mathrm{p}<0.05)$ was seen in both the raw and cooked lightness $\left(\mathrm{L}^{*}\right)$ values over time regardless of diet. This decrease in lightness over time indicates decreased visual chop pinkness as well as increased spoilage (Mancini et al 2005). Likewise, significant $(\mathrm{p}<0.05)$ diet by storage time interactions were seen in both the raw redness $\left(a^{*}\right)$ and yellowness $\left(b^{*}\right)$ measurements over time; these findings are consistent with those of Weigand and others (2002). However, unlike their report which showed an overall increase in yellowness scores among CLA supplemented hogs suggesting a less desirable pork product, the results of this study showed no significant differences among diet type and color values $(\mathrm{p}>0.05)$.

\section{Shear Force}

Pork loin tenderness is directly correlated to consumer likeability and acceptability. Tenderness is measured using a Warner Bratzler shear force attachment to assess peak force needed to shear a $1.27 \mathrm{~cm}$ core. The higher the force value needed to cut the meat product, the tougher the meat product is likely to be; however, as meat becomes more rancid, texture scores decrease due to increased oxidation (Nollet et al 2009). Texture scores indicated there was a significant decrease $(\mathrm{p}<0.05)$ in the sheering score of the control pork over time (Table 5). Although there was not a significant difference between the control pork and the CLA supplemented pork texture values, CLA pork had lower numerical shear force values. The texture of the CLA pork also decreased by smaller numerical increments throughout the storage period than the 
control pork showing possible increased shelf stability in regards to texture. The lower numerical texture scores for the CLA pork along with the increased texture reports through the sensory analysis indicate the CLA meat may be slightly tenderer than the control.

\section{TBARS}

It is hypothesized that CLA supplementation could decrease oxidation levels due to the overall increase in saturated fat (which is known to be more shelf stable and less susceptible to autoxidation reactions). In support of this claim, CLA samples were shown (Table 6) to have an overall decreased $(\mathrm{p}<0.05) \mathrm{mg}$ malondialdehyde (MDA) per $\mathrm{kg}$ sample values over the 7-d storage period; this finding is consistent with the results of Wiegand and others (2002). An interaction $(\mathrm{p}<0.05)$ between diet and day was also seen over the 7-d storage period. Although not significant, a trend of decreasing mg MDA / kg sample was seen for the control and CLA samples over the storage period. This trend indicates that lipid oxidation was controlled at $4^{\circ} \mathrm{C}$ for both diets. These results are consistent with the an increase in saturated fat content of the CLA pork measured by fatty acid profile by Barnes and others (2011).

\section{Proximate Composition of Loin}

Ash, moisture, and protein values in the pork samples were not affected $(\mathrm{p}<0.05)$ by treatment (Table 7). Raw fat content was not affected $(\mathrm{p}<0.05)$; however, CLA pork had a higher content of cooked fat than the control pork. Significant differences $(\mathrm{p}<$ 0.05) were seen in the fat content of the cooked samples between the control and the CLA diets, with the CLA showing an increased fat content. The varied fat content among the control and CLA groups can be attributed to the differing fat depots 
throughout the loin. The control meat contained greater amounts of subcutaneous fat (which was trimmed prior to and after cooking), while the CLA meat contained more intramuscular fat- therefore providing a higher fat composition. Although numerical increases were seen between the control and CLA protein values, these did not reach statistical differences.

\section{Sensory Evaluation}

Sensory panel results were based on an 8-point descriptive hedonic scale and are summarized in Table 8. Although no significant differences $(\mathrm{p}<0.05)$ were seen between the control and treatment for the parameters tested (flavor, juiciness, likability, tenderness, or off-flavor), numeric trends were seen for all 5 categories. The CLA pork had higher numeric scores than the control in regards to flavor (4.373 vs. 4.123), juiciness (4.588 vs. 4.251$)$, likeability (4.370 vs. 4.265$)$, and tenderness (4.698 vs. 4.436$)$. The similar sensory attribute scores indicate that although the CLA pork had numerical increases in the mean scores, CLA supplementation did not adversely or positively affect sensory characteristics in the pork loins. These findings support those of Wiegand and others (2002) and Dugan and others (1999) showing that CLA inclusion provided similar sensory results to the control meat. Unlike the findings of Janz and others (2008), the results of this study did not show an off-odor/flavor associated with the CLA meat.

\section{Conclusion}

CLA supplementation of barrows resulted in similar pork products to the traditional hog feed products. Although the CLA meat did appear to increase marbling, exhibit increased tenderness, and less susceptibility to oxidation over storage time, the results were seen only as numerical differences and failed to reach significance. An 
absence of a CLA affect $(\mathrm{p}<0.05)$ relative to pork quality indicates that traditionally fed hogs is a more practical approach in pork production. 


\section{References}

American Meat Science Association. (1995). In National Live Stock and Meat Board, American Meat Science Association (Ed.), Research guidelines for cookery, sensory evaluation and instrumental tenderness measurements of fresh meat. Chicago, Illinois: American Meat Science Association.

Corino, C., Magni, S., Pastorelli, G., Rossi, R., Mourot, J. 2003. Effect of conjugated linoleic acid on meat quality, lipid metabolism, and sensory characteristics of dry-cured hams from heavy pigs. Journal of Animal Science. 81(9), 2219-2229.

Dugan, M.E.R., Aalhus, J.L., Jeremiah, L.E., Kramer, J.K.G., Schaefer, A.L. (1999). The effects of feeding conjugated linoleic acid on subsequent pork quality. Canadian Journal of Animal Science. 79(1). 45-51.

Dugan, M. E. R., Kramer, J. K. G., \& Aalhus, J. L. (2004). Conjugated linoleic acid pork research. American Journal of Clinical Nutrition, 79(6), 1212s-1216s.

Fernandez, X., Monina, G., Talmanta, A., Mouroth, J., and Lebret, B. 1999. Influence of intramuscular fat content on the quality of pig meat - 1. Composition of the lipid fraction and sensory characteristics of $\mathrm{m}$. longissimus lumborum. Journal of Meat Science. 53(1), 59-65. 
Janz, J.A., Morel, P.C., Purchas, R.W., Corrigan, V.K., Cumarasamy, S., Wilkinson, B.H., Hendriks, W.H. 2008. The influence of diets supplemented with conjugated linoleic acid, selenium, and vitamin E, with or without animal protein, on the quality of pork from female pigs. Journal of Animal Science. 88(6), 1402-1409.

Jiang, Z. Y., Yang, L., Jiang, S. Q., Lin, Y. C., Zhong, W. J., \& Zheng, C. T. (2010). Conjugated linoleic acid differentially regulates fat deposition in backfat and longissimus muscle of finishing pigs. Journal of Animal Science, 88(5), 1694-1705.

Joo, S.T., Lee, J.I., Ha, Y.L., Park, G.B. 2002. Effects of dietary conjugated linoleic acid on fatty acid composition, lipid oxidation, color, and water-holding capacity of pork loin. Journal of Animal Science. 80. 108-112.

Larsen, S. T., Swan, J. E., Sparks, J. C., Wiegand, B. R., \& Parrish, F. C. J. (2009). Dietary conjugated linoleic acid changes belly and bacon quality from pigs fed varied lipid sources. Journal of Animal Science, 87(1), 285-295.

Mancini, R.A., Hunt, M.C. 2005. Current research in meat color. Journal of Meat Science. 71:100. 121.

Moya-Camarena, S. Y., Vanden-Heuvl, J.P., Blachard, S.G., Leesnitzer, L.A., Belury, M.A. (1999). Conjugated Linoleic Acid is a potent naturally occurring ligand and activator of PPAR. Journal of Lipid Research. 40. 1426-1433. 
Nollet, L. M., Toldra, F. 2009. Handbook of Muscle Foods Analysis. CRC Press, Taylor and Francis Group, Boca Raton, FL.

Spanier, A.M., Traylor, R.D. 1991. A rapid, direct chemical assay for the quantitative determination of thiobarbituric acid reactive substances in raw, cooked, and cooked/stored muscle foods. Journal of Muscle Foods. 2. 165-176.

Spiteller, G. 2005. Furan fatty acids: occurrence, synthesis, and reactions. Are furan fatty acids responsible for the cardioprotective effects of a fish diet? Journal of Lipids. 40(8), $755-771$.

Wiegand, B. R., Larsen, S. T., Baas, T. J., Parrish, F. C. J., \& Swan, J. E. (2001). Conjugated linoleic acid improves feed efficiency, decreases subcutaneous fat, and improves certain aspects of meat quality in stress-genotype pigs. Journal of Animal Science, 79(8), 2187-2195.

Wiegand, B. R., Sparks, J. C., Parrish, F. C., Jr, \& Zimmerman, D. R. (2002). Duration of feeding conjugated linoleic acid influences growth performance, carcass traits, and meat quality of finishing barrows. [Duration of feeding conjugated linoleic acid influences growth performance, carcass traits, and meat quality of finishing barrows] Journal of Animal Science, 80, 637-643. 


\section{TABLES}

Table 1. Diet formulation calculated (as-fed basis) of diets shown below. Both control and CLA diets only differed in the $1.00 \%$ oil additive.

\begin{tabular}{|l|l|}
$\begin{array}{l}\text { Composition and calculated analysis (as-fed basis) of diets. } \\
\text { Ingredient }\end{array}$ & Inclusion, \% \\
Corn & 84.99 \\
Soybean meal & 10.83 \\
Meat \& bone meal & 2.11 \\
Oil $^{1}$ & 1.00 \\
Limestone $^{1}$ & 0.65 \\
Vitamin and trace mineral premix & 0.25 \\
Salt & 0.17 \\
Lysine & 0.005 \\
Calculated analysis & \\
Crude protein, \% & 13.55 \\
ME, kcal/kg & 3265.61 \\
Lysine, \% & 0.60 \\
Calcium, \% & 0.50 \\
Phosphorus, available \% & 0.19
\end{tabular}

${ }^{1}$ Soybean oil or CLA-60 (60\% CLA isomers, 50:50 c9,t11:t10,c12; provided by BASF) in their respective diet treatments. 
Table 2. Change in muscle $\mathrm{pH}$ of control and treatment (CLA) in both raw and cooked pork loin samples over a 7-d storage period. Although an interaction was seen over time $(\mathrm{p}<0.05)$, changes were independent of diet

\begin{tabular}{c|cc|lc}
\hline & \multicolumn{2}{c|}{ Raw } & \multicolumn{2}{c}{ Cooked } \\
Day & \multicolumn{1}{c}{ Control } & \multicolumn{1}{c}{ CLA } & Control & \multicolumn{1}{c}{ CLA } \\
\hline $\mathbf{1}$ & $5.676 \pm 0.018^{\mathrm{B}}$ & $5.698 \pm 0.017^{\mathrm{A}}$ & $5.982 \pm 0.02^{\mathrm{B}}$ & $5.982 \pm 0.02^{\mathrm{B}}$ \\
$\mathbf{3}$ & $5.813 \pm 0.05^{\mathrm{B}}$ & $5.864 \pm 0.04^{\mathrm{B}}$ & $6.121 \pm 0.11^{\mathrm{B}}$ & $5.999 \pm 0.02^{\mathrm{B}}$ \\
$\mathbf{5}$ & $6.326 \pm 0.09^{\mathrm{A}}$ & $6.095 \pm 0.09^{\mathrm{BC}}$ & $6.251 \pm 0.06^{\mathrm{AB}}$ & $6.251 \pm 0.10^{\mathrm{AB}}$ \\
$\mathbf{7}$ & $6.405 \pm 0.10^{\mathrm{A}}$ & $6.434 \pm 0.09^{\mathrm{A}}$ & $6.517 \pm 0.06^{\mathrm{A}}$ & $6.593 \pm 0.06^{\mathrm{A}}$ \\
\hline
\end{tabular}

Values are listed as mean scores $\pm S E(n=5)$ for each treatment on each treatment day. ${ }^{\mathrm{A}, \mathrm{B}}$ Differences indicate significant differences within columns over 7 days, Tukey's honestly significant difference test; $(\mathrm{p}<0.05)$ 